Article

\title{
Effects of Ultrasound-Assisted Extraction and Solvent on the Phenolic Profile, Bacterial Growth, and Anti-Inflammatory/Antioxidant Activities of Mediterranean Olive and Fig Leaves Extracts
}

\author{
Cristina Alcántara ${ }^{1}$, Tihana Žugčić ${ }^{2,3}$, Radhia Abdelkebir ${ }^{3,4}$, Jose V. García-Pérez ${ }^{5}$, \\ Anet Režek Jambrak ${ }^{2}$, José M. Lorenzo ${ }^{6}$ (D), María Carmen Collado 1,*(D), \\ Daniel Granato ${ }^{7, *(D)}$ and Francisco J. Barba ${ }^{3, *(D)}$ \\ 1 Department of Biotechnology, Institute of Agrochemistry and Food Technology, Spanish National Research \\ Council (IATA-CSIC), Av. Agustin Escardino 7, 46980 Valencia, Spain; crisalba@iata.csic.es \\ 2 Faculty of Food Technology and Biotechnology, University of Zagreb, Pierottijeva 6, 10000 Zagreb, Croatia; \\ tihana.zugcic@gmail.com (T.Ž.); arezek@pbf.hr (A.R.J.) \\ 3 Nutrition and Food Science Area, Preventive Medicine and Public Health, Food Science, \\ Toxicology and Forensic Medicine Department, Universitat de València, Avda. Vicent Andrés Estellés, \\ 46100 València, Spain; abdelkebirradhia@yahoo.fr \\ 4 Range Ecology Laboratory in the Institute of Arid Regions (IRA) of Medenine, 4100 Medenine, Tunisia \\ 5 Grupo de Análisis y Simulación de Procesos Agroalimentarios (ASPA), Departamento de Tecnología de \\ Alimentos, Universitat Politècnica de València, 46022 Valencia, Spain; jogarpe4@tal.upv.es \\ 6 Centro Tecnológico de la Carne de Galicia, Adva. Galicia n 4, Parque Tecnológico de Galicia, \\ San Cibrao das Viñas, 32900 Ourense, Spain; jmlorenzo@ceteca.net \\ 7 Food Processing and Quality, Production Systems Unit-Natural Resources Institute Finland (Luke)-Tietotie 2, \\ FI-02150 Espoo, Finland \\ * Correspondence: mcolam@iata.csic.es (M.C.C.); daniel.granato@luke.fi (D.G.); francisco.barba@uv.es (F.J.B.)
}

Academic Editors: Giancarlo Cravotto and Farid Chemat

Received: 2 March 2020; Accepted: 8 April 2020; Published: 9 April 2020

\begin{abstract}
Mediterranean plants, such as fig and olive leaves, are well-known to exert beneficial effects in humans because of the presence of a wide range of bioactive compounds. However, scarce information regarding the impact of extraction methods, such as ultrasound and types of solvents, on their profile of antioxidant and anti-inflammatory compounds is provided. In addition, no information is available on the effects of extraction methods and solvents on the inhibition of pathogenic bacteria or promoting probiotic growth. In this scenario, this study was aimed to study the effects of ultrasound-assisted extraction (UAE) and solvent on the phenolic profile (Triple TOF-LC-MS/MS), antioxidant and anti-inflammatory compounds of olive and fig leaves. Results showed that UAE extracted more carotenoids compared to conventional extraction, while the conventional extraction impacted on higher flavonoids (olive leaves) and total phenolics (fig leaves). The antioxidant capacity of aqueous extract of fig leaves was three times higher than the extract obtained with ethanol for conventional extraction and four times higher for UAE. In general terms, hydroethanolic extracts presented the highest bacterial growth inhibition, and showed the highest anti-inflammatory activity. In conclusion, these side streams can be used as sources of bioactive compounds for further development of high-added-value products.
\end{abstract}

Keywords: bioactive compounds; extraction techniques; reactive oxygen species; antioxidant methods; anti-inflammatory response; LC-MS 


\section{Introduction}

From ancient times, Mediterranean plants and trees have attracted the interest of human being due to their beneficial properties such as antiviral, anti-inflammatory, prevention of cardiovascular diseases, and improvement of lipid metabolism to reduce obesity [1]. Most of these health-related effects have been attributed to their high content in bioactive compounds, such as polyphenols and carotenoids [2-4]. Among the different Mediterranean fruits, olive and fig, especially their leaves, have attracted the consumer's attention because of their potential use as a source of traditional medicines, food additives, and preservatives. Additionally, some research studies showed that these materials can be used in nutrition and pharmaceutical industries [5,6]. As has been reported, fig leaves contain considerable amounts of antioxidants, especially phenolic compounds [1,5]. Oleuropein, hydroxytyrosol, luteolin-7-O-glucoside, verbascoside and apigenin-7-O-glucoside are the most abundant compounds and all display biologic activities including antioxidant, antimicrobial and antiproliferative properties [7]. Their chemical composition makes them well known for their therapeutic and medicinal properties for a long time showing great benefits on metabolism [8].

The daily consumption of the antioxidant compounds from olive and fig leaves may reduce the risk of non-communicable diseases, such as cardiovascular diseases by inhibiting in vivo oxidation of low density lipoproteins $[9,10]$. Therefore, at this stage of development, improving/intensification of extraction processes coupling novel technologies, such as ultrasound, to conventional treatments is of paramount importance for consumers and food/pharmaceutical companies. Ultrasound assisted extraction (UAE) allows either avoiding or minimizing the use of organic solvents to extract high-added value compounds, along with other beneficial properties including the reduction of treatment time, intensification of heat and mass transfer transport, increasing the extraction yields, better preserving high extract quality, and reducing the energy consumption [11,12]. Thereby, ultrasound assisted extraction (UAE) may involve energy, solvent and time savings, which have positive implications not only on process productivity and cost reduction but also on environmental impact (Figure 1).

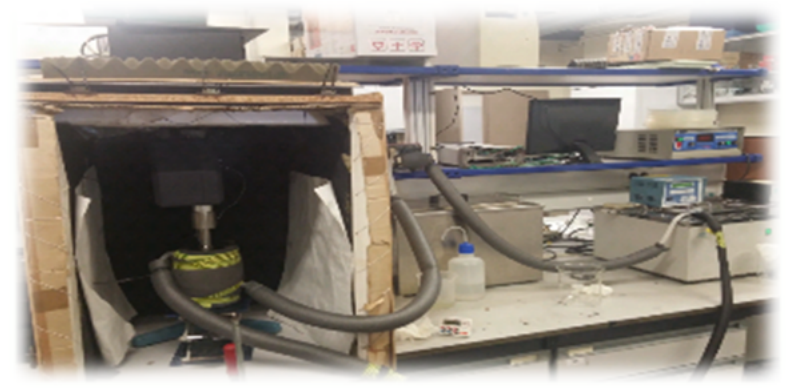

Figure 1. Experimental set-up for ultrasound assisted extraction.

For instance, the studies evaluating the use of UAE at mild temperatures $\left(<40{ }^{\circ} \mathrm{C}\right)$ from Mediterranean plant matrices is limited. In fact, there is only one previous study addressing the impact of UAE of polyphenols from olives leaves below room temperature [13]. The effect of UAE in liquid media is mainly attributed to cavitation phenomena, thus promoting stirring, and also to temperature increase associated to gas bubble implosion. However, although high temperatures could promote polyphenols extraction by increasing diffusion and solubility it could promote the degradation of thermolabile compounds $[13,14]$. Moreover, the phenomena linked to UAE are largely dependent on the extraction solvent used, which may also modify the phenolic profile of the extract as well as its bioactivity. In this regard, this works aims to assess the effect of conventional and ultrasound extraction at mild temperatures on the profile of antioxidant compounds of the different extracts obtained from dried fig and olive leaves using aqueous or hydroethanolic mixtures. Moreover, the impact of these extracts on the antioxidant capacity and anti-inflammatory response as well as their effect on bacterial growth, either pathogenic or potential beneficial bacteria will be evaluated. 


\section{Results and Discussion}

\subsection{Contents of Total Phenolics, Flavonoids, and Carotenoids}

The analysis of total phenolic content of different plant extracts obtained suggested that conventional extraction was more effective compared to an ultrasound assisted extraction regardless of solvent type (Figure 2).

a)

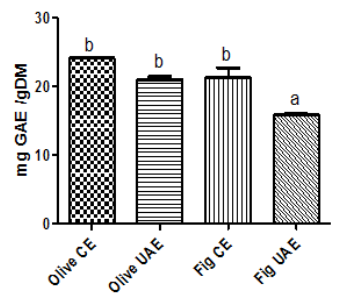

d)

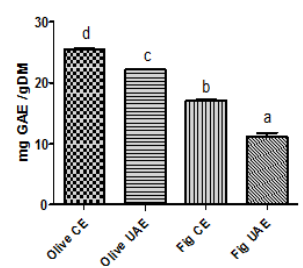

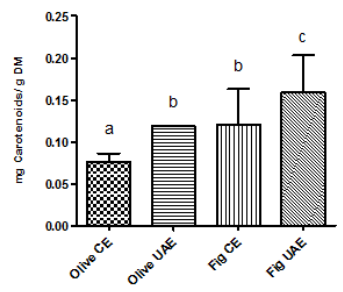

e)

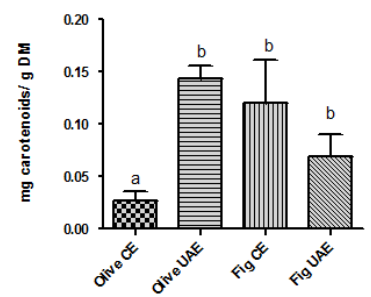

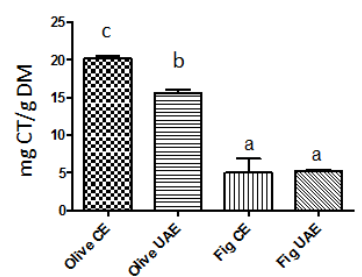

f)

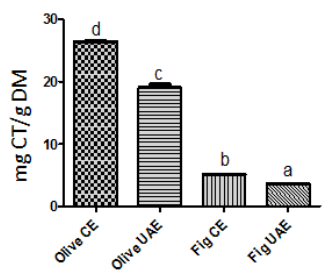

Figure 2. Content of total phenolics, flavonoids and carotenoids in fig and olive leaves extracts after conventional (CE) or ultrasound-assisted (UAE) extraction using either aqueous $(\mathbf{a}-\mathbf{c})$ or hydroethanolic (d-f) solvents. Total phenolic content (mg gallic acid equivalents (GAE)/g dry matter (DM)) (a,d), total flavonoid content ( $\mathrm{mg}$ catechin $(\mathrm{CT}) / \mathrm{g}$ DM) $(\mathbf{b}, \mathbf{e})$ and the carotenoids content (mg carotenoids/g DM sample) $(\mathbf{c}, \mathbf{f})$. Bars represent mean and standard error. Different letters comparing treatments represent statistically different mean values $(p<0.05)$.

In particular, results showed a higher total phenolic content for conventional extraction than for UAE. Our data displayed that the total phenolic content varied widely and ranged from 21.0 to $25.4 \mathrm{mg} \mathrm{GAE} / \mathrm{g} \mathrm{DM}$ for olive leaves and 11.1 to $21.2 \mathrm{mg} \mathrm{GAE} / \mathrm{g}$ DM for fig leaves, taking into consideration two extraction techniques and two types of solvent. The highest total phenolic content was obtained by the conventional method in both plant extracts. Regardless of the solvent type, olive leaves showed higher total phenolic content when extracted with hydroethanolic solutions for both CE (25.4 mg GAE/g DM) and UAE (22.2 mg GAE/g DM) procedures, which is lower than the results available in the literature for UAE [15-17]. The total phenolic content obtained with water using the CE was $24.1 \mathrm{mg}$ GAE/g DM, a concentration that was in line with values reported in the literature [18]. For fig leaves, higher total phenolic contents were obtained by aqueous extraction, both by $\mathrm{CE}$ and UAE (21.2 mg GAE/g DM versus $17.1 \mathrm{mg}$ GAE/g DM in water-CE and hydroethanolic-CE method, respectively). For UAE, the total phenolic content was lower: $15.8 \mathrm{mg}$ GAE/g DM in water and $11.128 \mathrm{mg} \mathrm{GAE} / \mathrm{g}$ DM in hydroethanolic solution. Lower contents were recently described by Mopuri, Ganjayi, Meriga, Koorbanally, and Islam [19].

The total flavonoids content was measured in both hydroethanolic and aqueous extracts of olive and fig leaves with ultrasound assisted and conventional extractions (Figure 2). Plant extracts obtained with the CE presented a higher $(p<0.05)$ total flavonoids content than extracts obtained with UAE, except for fig leaves where with UAE water extracts showed slightly higher values (5.2 mg CT/g DM) than in ethanol (3.7 $\mathrm{mg} \mathrm{CT/g} \mathrm{DM).} \mathrm{Hydroethanolic} \mathrm{extracts} \mathrm{obtained} \mathrm{with} \mathrm{the} \mathrm{CE} \mathrm{method} \mathrm{showed} \mathrm{a}$ concentration of $5.1 \mathrm{mg} \mathrm{CT} / \mathrm{g}$ DM in ethanol and $5.0 \mathrm{mg} \mathrm{CT} / \mathrm{g}$ DM in water. Total carotenoids content 
was influenced by the extraction method, mainly by the UAE extraction, especially for fig leaves which aqueous extracts had shown the significant highest level of $0.16 \mathrm{mg}$ carotenoids/g (Figure 2). Regarding CE, no significant difference between two solvents was found $(p>0.05)$ in fig leaves. On the other hand, the extracts obtained with UAE presented higher total carotenoid content for olive leaves $(0.12$ $\mathrm{mg}$ carotenoid/g DM in water and $0.14 \mathrm{mg}$ carotenoids/g DM in ethanol).

Although the benefits of ultrasound assisted extraction are well established in the previous literature, the results reported here confirm that its performance is strongly dependent on the process parameters used. Furthermore, ultrasound application is not efficient for every plant equally, as well as for extraction of certain compounds. The used process parameters were chosen from the literature research of optimal conditions for the highest values of extracted compounds [13,15]. Ultrasound exerts different phenomena when applied at high power in a liquid medium. The main effect of UAE is linked to the cavitation of air bubbles which involves large local release of mechanical and thermal energy into the medium, creating high local turbulence and temperature rise. In addition, alternating compression and expansions produced by ultrasound wave when propagating through the liquid bulk also increase turbulence $[13,15]$. Thereby, ultrasound application mainly reduces external resistance to mass transport improving the contact between the solvent and the sold matrix. In addition, it has also been reported the ultrasound ability to release components strongly attached to the solid matrix as well as to speed-up the molecular internal diffusion.

\subsection{Individual Phenolic Composition, Antioxidant Capacity and Anti-Inflammatory Effects}

Olive leaves were rich in total phenolic content and demonstrated a good antioxidant capacity. This is mainly caused by phenolic compounds such as oleuropein, hydroxytyrosol and verbascoside (and derivatives), detected in the aqueous extract (Table 1) and to a much lesser extent by, for instance, tocopherols. The antioxidant capacity results are reported in Figure 3A.

Table 1. Triple TOF-LC-MS-MS analysis of the polyphenols $(\mathrm{mg} / \mathrm{kg})$ in aqueous olive leaves extracts obtained with conventional (CE) and ultrasound-assisted (UAE) procedures.

\begin{tabular}{|c|c|c|c|c|}
\hline Compound Name & Formula & Expected $m / z$ & $\mathrm{CE}$ & UAE \\
\hline Oleoside 11-methylester & $\mathrm{C}_{17} \mathrm{H}_{24} \mathrm{O}_{11}$ & 403.1246 & $18537 \pm 151$ & $18128 \pm 290$ \\
\hline Rhoifolin & $\mathrm{C}_{27} \mathrm{H}_{30} \mathrm{O}_{14}$ & 577.1563 & $6932 \pm 574$ & $6123 \pm 429$ \\
\hline Demethyloleuropein & $\mathrm{C}_{24} \mathrm{H}_{30} \mathrm{O}_{13}$ & 525.1614 & $5676 \pm 317$ & $4692 \pm 143$ \\
\hline Querc-3-O-gal-7-O-rhamnoside & $\mathrm{C}_{27} \mathrm{H}_{30} \mathrm{O}_{16}$ & 609.1461 & $3555 \pm 319$ & $2651 \pm 137$ \\
\hline Phloretin xylosyl-galactoside & $\mathrm{C}_{26} \mathrm{H}_{32} \mathrm{O}_{14}$ & 567.1719 & $4164 \pm 222$ & $3369 \pm 124$ \\
\hline 3-Hydroxyphloretin 2-O-xylosyl-gluc & $\mathrm{C}_{26} \mathrm{H}_{32} \mathrm{O}_{15}$ & 583.1668 & ND & $956 \pm 57$ \\
\hline Kaempferol 3-rutinoside & $\mathrm{C}_{27} \mathrm{H}_{30} \mathrm{O}_{15}$ & 593.1512 & ND & $2682 \pm 213$ \\
\hline Kaempferol 3-O-sophoroside & $\mathrm{C}_{27} \mathrm{H}_{30} \mathrm{O}_{16}$ & 609.1461 & $3555 \pm 319$ & $2651 \pm 137$ \\
\hline Verbascoside & $\mathrm{C}_{29} \mathrm{H}_{36} \mathrm{O}_{15}$ & 623.1981 & $2692 \pm 21$ & $2250 \pm 122$ \\
\hline Apigenin 6-C-glucoside & $\mathrm{C}_{21} \mathrm{H}_{20} \mathrm{O}_{10}$ & 431.0984 & $1956 \pm 61$ & $1593 \pm 100$ \\
\hline 1-Sinapoyl-2-feruloylgentiobiose & $\mathrm{C}_{33} \mathrm{H}_{40} \mathrm{O}_{18}$ & 723.2142 & $1622 \pm 124$ & $1601 \pm 153$ \\
\hline Isorhamnetin 7-O-rhamnoside & $\mathrm{C}_{22} \mathrm{H}_{22} \mathrm{O}_{11}$ & 461.1089 & $1457 \pm 125$ & $1083 \pm 101$ \\
\hline Hydroxytyrosol & $\mathrm{C}_{8} \mathrm{H}_{10} \mathrm{O}_{3}$ & 153.0557 & $766 \pm 26$ & $646 \pm 13$ \\
\hline Diosmin & $\mathrm{C}_{28} \mathrm{H}_{32} \mathrm{O}_{15}$ & 607.1668 & $649 \pm 21$ & $548 \pm 36$ \\
\hline $\begin{array}{l}\text { Kaempferol } \\
\text { 3-O-rhamnosyl-rhamnosyl-oluc }\end{array}$ & $\mathrm{C}_{33} \mathrm{H}_{40} \mathrm{O}_{19}$ & 739.2091 & $639 \pm 32$ & $616 \pm 19$ \\
\hline Hydroxytyrosol 1-O-glucoside & $\mathrm{C}_{14} \mathrm{H}_{20} \mathrm{O}_{9}$ & 331.1035 & $667 \pm 81$ & $671 \pm 23$ \\
\hline Protocatechuic acid 4-O-glucoside & $\mathrm{C}_{13} \mathrm{H}_{16} \mathrm{O}_{9}$ & 315.0722 & $595 \pm 17$ & $488 \pm 17$ \\
\hline Sinapoyl glucose & $\mathrm{C}_{17} \mathrm{H}_{22} \mathrm{O}_{10}$ & 385.114 & $488 \pm 24$ & ND \\
\hline Matairesinol & $\mathrm{C}_{20} \mathrm{H}_{22} \mathrm{O}_{6}$ & 357.1344 & $455 \pm 27$ & $506 \pm 18$ \\
\hline Kaempferol & $\mathrm{C}_{15} \mathrm{H}_{10} \mathrm{O}_{6}$ & 285.0405 & $474 \pm 65$ & $216 \pm 50$ \\
\hline$p$-HPEA-EA & $\mathrm{C}_{19} \mathrm{H}_{22} \mathrm{O}_{7}$ & 361.1293 & $350 \pm 61$ & ND \\
\hline 3,4-DHPEA-EA & $\mathrm{C}_{19} \mathrm{H}_{22} \mathrm{O}_{8}$ & 377.1242 & ND & $929 \pm 139$ \\
\hline 3-Methylcatechol & $\mathrm{C}_{7} \mathrm{H}_{8} \mathrm{O}_{2}$ & 123.0452 & $339 \pm 58$ & ND \\
\hline Quercetin 3-O-glucoside & $\mathrm{C}_{21} \mathrm{H}_{20} \mathrm{O}_{12}$ & 463.0882 & $294 \pm 8$ & $171 \pm 28$ \\
\hline Oleoside dimethylester & $\mathrm{C}_{18} \mathrm{H}_{26} \mathrm{O}_{11}$ & 417.1402 & $285 \pm 9$ & $201 \pm 22$ \\
\hline 4-Hydroxybenzoic acid 4-O-gluc & $\mathrm{C}_{13} \mathrm{H}_{16} \mathrm{O}_{8}$ & 299.0772 & $185 \pm 5$ & $156 \pm 11$ \\
\hline$p$-Coumaric acid & $\mathrm{C}_{9} \mathrm{H}_{8} \mathrm{O}_{3}$ & 163.0401 & $170 \pm 1$ & $126 \pm 23$ \\
\hline Dihydroquercetin 3-O-glucoside & $\mathrm{C}_{21} \mathrm{H}_{22} \mathrm{O}_{12}$ & 465.1039 & $163 \pm 16$ & $117 \pm 12$ \\
\hline 3-Sinapoylquinic acid & $\mathrm{C}_{18} \mathrm{H}_{22} \mathrm{O}_{10}$ & 397.114 & $111 \pm 13$ & ND \\
\hline Quercetin & $\mathrm{C}_{15} \mathrm{H}_{10} \mathrm{O}_{7}$ & 301.0354 & $46 \pm 5$ & ND \\
\hline Rosmadial & $\mathrm{C}_{20} \mathrm{H}_{24} \mathrm{O}_{5}$ & 343.1551 & ND & $79 \pm 45$ \\
\hline
\end{tabular}

ND: Not detected. Querc-3-O-gal-7-O-rhamnoside: Quercetin 3-O-galactoside 7-O-rhamnoside. Gluc: glucoside. 
A)

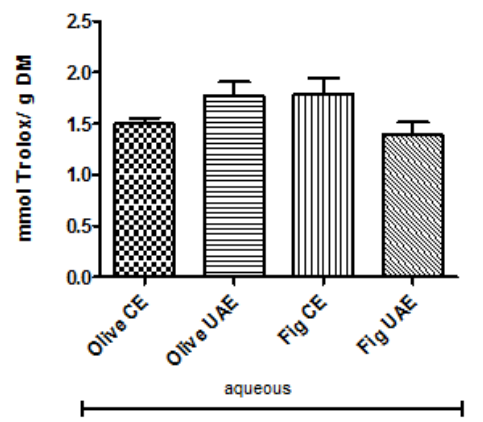

B)

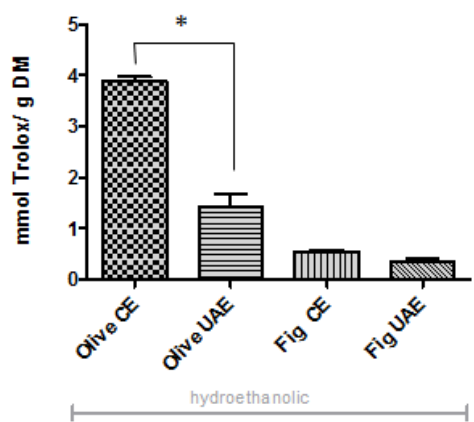

C)

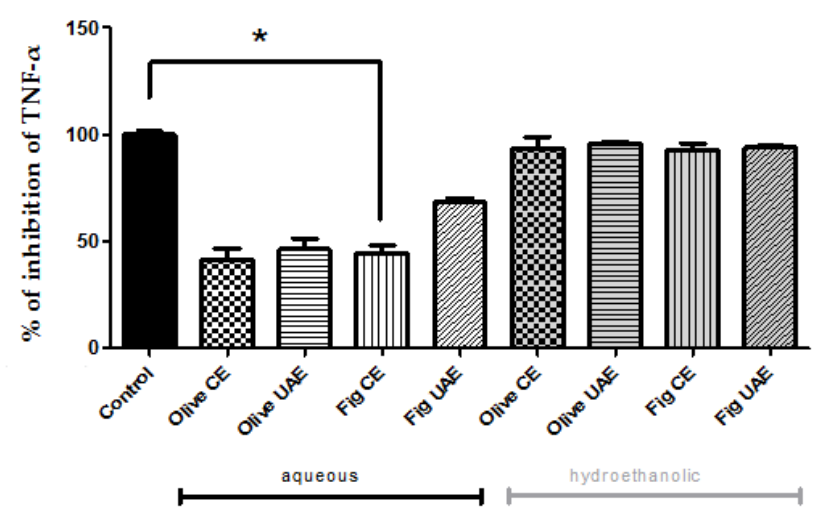

Figure 3. Antioxidant capacity and anti-inflammatory effects of the fig and olive leaves extracts. Antioxidant capacity (TEAC; Trolox Equivalent Antioxidant Capacity (mmol Trolox/g dry matter)) in (A) aqueous and (B) hydroethanolic (50:50, v/v, ethanol: water) extracts. (C) The effect of plant extracts on the TNF- $\alpha$ inhibition determined in olive and fig leaves after conventional (CE) or ultrasound-assisted (UAE) extraction. Differences $(p<0.05)$ between treatments are denoted by *

In particular, extracts obtained with the conventional method presented a higher antioxidant activity compared to the extracts obtained with UAE. Among the plants analyzed, olive leaves extracted with ethanol/water mixture in the CE way showed the largest antioxidant activity $(7.8 \mathrm{mmol} \mathrm{TE})$ which was indicated by their high level of phenolic compounds, so the processing of olives changes the profile of phenolic compounds and therefore, both the organoleptic properties and the antioxidant capacity of the product.

The aqueous extract of fig leaves showed an antioxidant capacity three times higher than the extract obtained with ethanol for conventional extraction and four times higher for UAE. This might be attributed to the different polarity of water, thus modifying the solubility of the different target compounds $[3,20]$. Fig leaves presented the lowest antioxidant activity compared to the olive leaves (Figure 2). The levels of phytochemical phenolics and flavonoids compounds found in figs are strongly influenced by various factors such as the color, the part of fruit, the maturity and the drying process. Gallic acid, chlorogenic acid, quercetin-3-rutinoside and (-)-epicatechin are the most predominant phenolic acids and flavonoids in dried and fresh fig varieties [21] (Table 2). 
Table 2. Triple TOF-LC-MS-MS analysis of the polyphenols $(\mathrm{mg} / \mathrm{kg})$ in aqueous fig leaves extracts obtained with conventional (CE) and ultrasound-assisted (UAE) extraction procedures.

\begin{tabular}{|c|c|c|c|c|}
\hline Compound Name & Formula & Expected $m / z$ & CE & UAE \\
\hline $\begin{array}{l}\text { Apigenin 6-C-glucoside } \\
\text { 8-C-arabinoside }\end{array}$ & $\mathrm{C}_{26} \mathrm{H}_{28} \mathrm{O}_{14}$ & 563.1406 & $16475 \pm 2471$ & $11765.26 \pm 1038$ \\
\hline Apigenin 6-C-glucoside & $\mathrm{C}_{21} \mathrm{H}_{20} \mathrm{O}_{10}$ & 431.0984 & $886 \pm 30$ & $509 \pm 112$ \\
\hline Quercetin 3- rutinoside & $\mathrm{C}_{27} \mathrm{H}_{30} \mathrm{O}_{16}$ & 609.1461 & $5008 \pm 504$ & $3539 \pm 114$ \\
\hline Rhoifolin & $\mathrm{C}_{27} \mathrm{H}_{30} \mathrm{O}_{14}$ & 577.1563 & $860 \pm 83$ & $578 \pm 29$ \\
\hline 3-Feruloylquinic acid & $\mathrm{C}_{17} \mathrm{H}_{20} \mathrm{O}_{9}$ & 367.1035 & $2115 \pm 126$ & $417 \pm 63$ \\
\hline 4-Hydroxycoumarin & $\mathrm{C}_{9} \mathrm{H}_{6} \mathrm{O}_{3}$ & 161.0244 & $1280 \pm 180$ & $719 \pm 157$ \\
\hline Ferulic acid & $\mathrm{C}_{10} \mathrm{H}_{10} \mathrm{O}_{4}$ & 193.0506 & $515 \pm 97$ & $292 \pm 47$ \\
\hline Kaempferol 3-O-xylosyl-glucoside & $\mathrm{C}_{26} \mathrm{H}_{28} \mathrm{O}_{15}$ & 579.1355 & $864 \pm 71$ & $602 \pm 86$ \\
\hline $\begin{array}{c}\text { Kaempferol } \\
\text { 3-O-xylosyl-rutinoside }\end{array}$ & $\mathrm{C}_{32} \mathrm{H}_{38} \mathrm{O}_{19}$ & 725.1935 & ND & $238 \pm 27$ \\
\hline 3-Sinapoylquinic acid & $\mathrm{C}_{18} \mathrm{H}_{22} \mathrm{O}_{10}$ & 397.114 & $1294 \pm 73$ & $395 \pm 73$ \\
\hline Sinapoyl glucose & $\mathrm{C}_{17} \mathrm{H}_{22} \mathrm{O}_{10}$ & 385.114 & $751 \pm 162$ & $485 \pm 99$ \\
\hline Kaempferol 3-O-rhamnoside & $\mathrm{C}_{21} \mathrm{H}_{20} \mathrm{O}_{10}$ & 431.0984 & $886 \pm 30$ & $509 \pm 112$ \\
\hline Kaempferol 3-O-rutinoside & $\mathrm{C}_{27} \mathrm{H}_{30} \mathrm{O}_{15}$ & 593.1512 & $570 \pm 16$ & $368 \pm 31$ \\
\hline Isorhamnetin 7-O-rhamnoside & $\mathrm{C}_{22} \mathrm{H}_{22} \mathrm{O}_{11}$ & 461.1089 & $511 \pm 26$ & $285 \pm 37$ \\
\hline p-Coumaroyl malic acid & $\mathrm{C}_{13} \mathrm{H}_{12} \mathrm{O}_{7}$ & 279.051 & $184 \pm 25$ & ND \\
\hline Resveratrol & $\mathrm{C}_{14} \mathrm{H}_{12} \mathrm{O}_{3}$ & 227.0714 & $177 \pm 37$ & $98 \pm 37$ \\
\hline Didymin & $\mathrm{C}_{28} \mathrm{H}_{34} \mathrm{O}_{14}$ & 593.1876 & $145 \pm 18$ & ND \\
\hline Chrysoeriol & $\mathrm{C}_{16} \mathrm{H}_{12} \mathrm{O}_{6}$ & 299.0561 & $128 \pm 46$ & ND \\
\hline Oleoside 11-methylester & $\mathrm{C}_{17} \mathrm{H}_{24} \mathrm{O}_{11}$ & 403.1246 & $128 \pm 15$ & $70 \pm 24$ \\
\hline $\begin{array}{l}\text { 4-Hydroxybenzoic acid } \\
\text { 4-O-glucoside }\end{array}$ & $\mathrm{C}_{13} \mathrm{H}_{16} \mathrm{O}_{8}$ & 299.0772 & $104 \pm 22$ & ND \\
\hline Rosmadial & $\mathrm{C}_{20} \mathrm{H}_{24} \mathrm{O}_{5}$ & 343.1551 & $60 \pm 26$ & $101 \pm 80$ \\
\hline Protocatechuic acid 4-O-glucoside & $\mathrm{C}_{13} \mathrm{H}_{16} \mathrm{O}_{9}$ & 315.0722 & $187 \pm 5$ & $120 \pm 14$ \\
\hline $\begin{array}{c}\text { Cyanidin } \\
\text { 3-O-(6-succinyl-glucoside) }\end{array}$ & $\mathrm{C}_{25} \mathrm{H}_{25} \mathrm{O}_{14}$ & 548.1172 & $86 \pm 13$ & $39 \pm 7$ \\
\hline Dihydrocaffeic acid & $\mathrm{C}_{9} \mathrm{H}_{10} \mathrm{O}_{4}$ & 181.0506 & $29 \pm 10$ & $13 \pm 5$ \\
\hline $\begin{array}{l}\text { Quercetin } \\
\text { 3-O-glucosyl-rhamnosyl-glucoside }\end{array}$ & $\mathrm{C}_{33} \mathrm{H}_{40} \mathrm{O}_{21}$ & 771.1989 & $155 \pm 138$ & $154 \pm 22$ \\
\hline
\end{tabular}

Note: ND: Not detected.

The anti-inflammatory activity of fig/olive leaves extracts are shown in Figure $3 \mathrm{C}$ and it is possible to observe that the hydroethanolic extracts presented higher inhibition of TNF- $\alpha$ compared to the aqueous extracts. The high content of polyphenols in these extracts can easily explain this observation as these compounds seem to modulate the secretion of pro-inflammatory markers [22]. Peyrol, Riva, and Amiot [23] reported that the conversion of oleuropein into hydroxytyrosol (HT) has been associated to health benefits like the improvement of lipid and glycaemia profile and also the reduction of inflammatory processes and oxidative stress. HT is the major anti-inflammatory compound in aqueous olive extracts in inflammatory response induced by LPS in macrophages (mediated by inhibition of NO production, diminished secretion of cytokines and chemokines [24]. The content of HT in aqueous CE and UAE olive extracts (766 \pm 26 and $646 \pm 13 \mathrm{mg} / \mathrm{kg}$, respectively) could explain the anti-inflammatory effect observed in our cellular model of inflammation.

The two main compounds present in aqueous leaves fig extracts, apigenin and quercetin are flavonoids (a flavone and flavonol, respectively), strongly related to anti-inflammatory activity. Apigenin, a flavonoid more abundant in the aqueous extract of fig leaves (Table 3) is also found in parsley and celery and it has been described that it inhibits the LPS-induced pro-inflammatory cytokines expression by inactivating NF- $\mathrm{kB}$. Moreover, the intake of apigenin also showed immunomodulation effects triggered by TNF- $\alpha$ in a mouse model of rheumatoid arthritis [25]. Quercetin, a ubiquitous plant secondary metabolite, is found abundant in onions, broccoli, apples, grapes, wine, tea, and leafy green vegetables, is well known as a potent antioxidant and anti-inflammatory agent. In aqueous extracts, this flavonol was very abundant (Table 3) and could be exerting part of the anti-inflammatory effect observed in the cell line HT-29 clone \#16. 
Table 3. Effect of olive and fig leaves extracts in the growth rate and maximal optical density of bacteria strain.

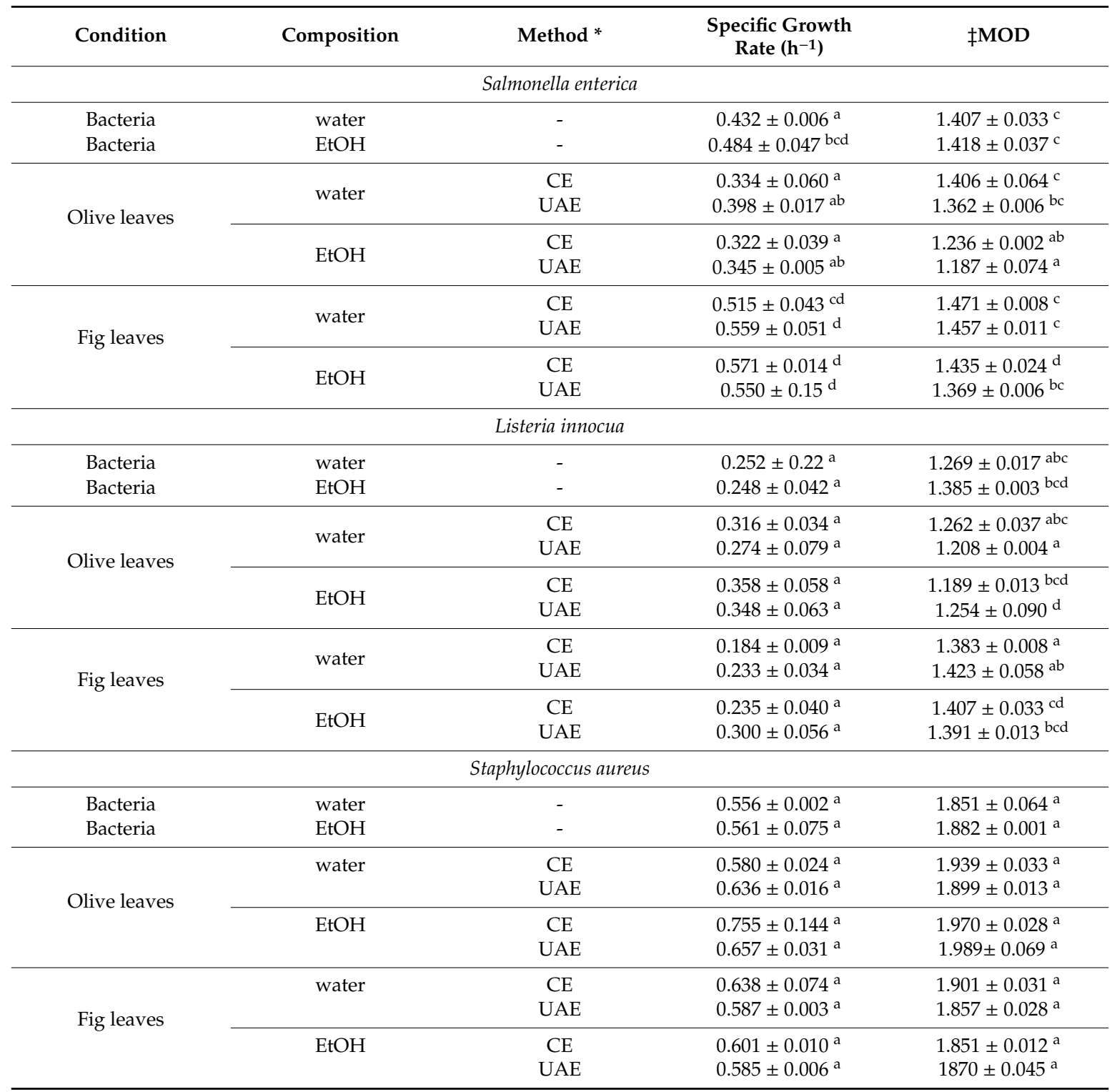

Note: EtOH = Ethanol: * Method: Conventional extraction (CE) and ultrasound-assisted extraction (UAE). ŁMOD: Maximal optical density measured at $595 \mathrm{~nm}$. Different letters in the same column represent statistically significant differences $(p<0.05)$.

\subsection{Effect of Extracts on Bacterial Growth}

Different effects on bacterial growth were observed for the extracts, which seem to depend on the plant, solvent, methods and bacterial strain used (Tables 3 and 4).

Regardless of the extraction method, only the hydroethanolic extracts had antibacterial effect against Salmonella enterica. The specific growth rate was reduced between 35\%-29\% in presence of CE and UAE hydroethanolic extract, respectively (Table 3). Additionally, the DOmax obtained from the antimicrobial effect of leaves olive extract against Salmonella enterica can be explained by the presence of numerous bioactive compounds such as phenolic compounds (oleuropein, verbascoside, quercetin-3-rutinoside, luteolin 7-glucoside). The main phenolic compounds detected in olive leaves was oleoside, which could exert an important antibacterial effect as demonstrated by Medina, Romero-Gil, Garrido-Fernández, and Arroyo-López [26]. This study reported the survival of pathogens (Escherichia coli, Staphylococcus aureus, Listeria monocytogenes, and Salmonella enterica) in olive brines, 
and described that the most influential phenols on microbial survival were EDA (dialdehydic form of decarboxymethyl elenolic acid), HyEDA (EDA linked to hydroxytyrosol), hydroxytyrosol 4-glucoside, tyrosol, and oleoside 11-methyl ester. In addition, a review of sources and biological activities of rhoifolin summarized the effect antimicrobial of this flavonoid compound against $E$. coli [27]. This is another of the major components of olive leaves $(6932 \pm 574$ and $61,230 \pm 429 \mathrm{mg} / \mathrm{kg}$, for CE and UAE extraction method, respectively) that may be exerting inhibition against $S$. enterica.

Table 4. Effect of olive and fig leaves extracts in the growth rate and maximal optical density of probiotic bacteria strain.

\begin{tabular}{|c|c|c|c|c|}
\hline Condition & Composition & Method & $\begin{array}{l}\text { Specific Growth } \\
\text { Rate }\left(h^{-1}\right)\end{array}$ & ‡MOD \\
\hline \multicolumn{5}{|c|}{ Lactobacillus casei } \\
\hline Bacteria & $\mathrm{EtOH}$ & - & $0.383 \pm 0.003^{a}$ & $2.837 \pm 0.018^{a b}$ \\
\hline \multirow{3}{*}{ Olive leaves } & water & $\mathrm{CE}$ & $0.398 \pm 0.016^{a}$ & $2.857 \pm 0.058^{a b}$ \\
\hline & \multirow{2}{*}{$\mathrm{EtOH}$} & $\mathrm{CE}$ & $0.383 \pm 0.008^{a}$ & $2.904 \pm 0.071 \mathrm{abc}$ \\
\hline & & UAE & $0.398 \pm 0.007^{a}$ & $2.852 \pm 0.083^{a b}$ \\
\hline \multirow{2}{*}{ Fig leaves } & \multirow{2}{*}{ water } & $\mathrm{CE}$ & $0.437 \pm 0.002^{b}$ & $3.077 \pm 0.023^{c}$ \\
\hline & & UAE & $0.441 \pm 0.003^{b}$ & $3.024 \pm 0.041 b c$ \\
\hline \multicolumn{5}{|c|}{ Bifidobacterium lactis } \\
\hline Bacteria & water & - & $0.234 \pm 0.021^{a}$ & $2.451 \pm 0.052^{\mathrm{a}}$ \\
\hline Bacteria & $\mathrm{EtOH}$ & & $0.236 \pm 0.016^{a}$ & $2.463 \pm 0.095^{a}$ \\
\hline \multirow{4}{*}{ Olive leaves } & \multirow{2}{*}{ water } & $\mathrm{CE}$ & $0.255 \pm 0.008^{a}$ & $2.634 \pm 0.081^{a}$ \\
\hline & & UAE & $0.223 \pm 0.005^{\mathrm{a}}$ & $2.461 \pm 0.013^{a}$ \\
\hline & \multirow{2}{*}{$\mathrm{EtOH}$} & $\mathrm{CE}$ & $0.233 \pm 0.011^{a}$ & $2.492 \pm 0.047^{\mathrm{a}}$ \\
\hline & & UAE & $0.229 \pm 0.017^{a}$ & $2.481 \pm 0.008^{a}$ \\
\hline \multirow{3}{*}{ Fig leaves } & \multirow[t]{2}{*}{ water } & $\mathrm{CE}$ & $0.252 \pm 0.003^{a}$ & $2.481 \pm 0.013^{a}$ \\
\hline & & UAE & $0.263 \pm 0.007^{a}$ & $2.540 \pm 0.036^{\mathrm{a}}$ \\
\hline & $\mathrm{EtOH}$ & $\mathrm{CE}$ & $0.217 \pm 0.006^{\mathrm{a}}$ & $2.386 \pm 0.050^{a}$ \\
\hline
\end{tabular}

Note: $\mathrm{EtOH}=$ Ethanol: * Method: Conventional extraction (CE) and ultrasound-assisted extraction (UAE). ‡MOD: Maximal optical density measured at $595 \mathrm{~nm}$. Different letters in the same column represent statistically significant differences $(p<0.05)$

Regarding the impact of plant extract on the growth of potential beneficial bacteria, it was observed an improvement of the Lactobacillus casei growth in aqueous extract of fig leaves, whereas no impact was found for Bifidobacterium lactis growth (Table 4). Many examples have been described of the antibacterial activity of flavonoids (such as apigenin and quercetin), which were extracted in relative high concentrations of fig leaves [28-31]. But little has been studied of a prebiotic effect of these compounds [32]. Some studies show that polyphenols can stimulate commensal and beneficial microbiota growth, while pathogenic strains can be inhibited [33]. In addition, Duda-Chodak [34] demonstrated that flavonoid aglycones, but not their glycosides, may inhibit growth of some intestinal bacteria. In this study also was observed slight stimulation of the growth of Lactobacillus spp. by quercetin-3-rutinoside. The extract of fig leaves contains quercetin-3-rutinoside at a high concentration (5008 \pm 504 and $3539 \pm 114 \mathrm{mg} / \mathrm{kg}$, for CE and UAE methodology, respectively) that can explain the enhanced growth of $L$. casei. It has been suggested that several hydrolyzed and/or derived products from the catabolism of polyphenols by intestinal bacteria could exert both their physiological functions in the digestive tract, as well as their prebiotic properties and their modification of the gut microbiota [35]. 


\section{Materials and Methods}

\subsection{Plant Materials}

Olive (Olea europaea) and fig (Ficus carica) leaves were collected from MonteVedat-Torrent (Valencia, Spain) in September 2017, dried in a tunnel microwave dryer (Shandong Adasen Trade Co, JN-100, Beijing, China) overnight for $12 \mathrm{~h}\left(1200 \mathrm{~W}, 70^{\circ} \mathrm{C}\right)$, then milled and stored at room temperature until being analyzed. Drying conditions were selected according to previous works due to its effect on antioxidant bioactive properties [36,37]. The authenticity of the plant materials was confirmed by the evaluation of the morphological structure of the leaves made by experts in the Department of Plant Biology of the University of Valencia, Spain.

\subsection{Chemical Reagents}

HPLC-grade solvents (acetonitrile, methanol and formic acid), Folin-Ciocalteu reagent, gallic acid, (+)-catechin, ABTS radical 2,2'-azinobis-(3-ethylbenzothiazoline-6-sulfonic acid), Trolox (6-hydroxy-2,5,7,8-tetramethylchroman-2-carboxylic acid, 97\% purity) were purchased from Sigma-Aldrich (St. Louis, MO, USA). De Man, Rogosa, and Sharpe (MRS) agar and broth were acquired in Sigma-Aldrich (Darmstadt, Germany). All other chemical reagents were of analytical grade.

\subsection{Solvents and Extraction Methodology}

Extraction experiments were carried out using two approaches: (1) distilled water (100\%, v/v) and (2) hydro-alcoholic solution $(50 \%, \mathrm{v} / \mathrm{v})$. A ratio of $2 \%(\mathrm{w} / \mathrm{v})$ and a total volume of $400 \mathrm{~mL}$ of solvent were used for each experiment and by use of two methods: (1) UAE and (2) conventional extraction (CE). It is noteworthy that the plant material:solvent ratio used in the current research is a preliminary experiment. Thus, any exploitation of the plant materials should be performed under more competitive conditions, e.g., at higher temperature or under UAE using flow-reactors.

UAE experiments were conducted using an ultrasonic probe system (UP400S, Dr. Hielscher, Teltow, Germany) at a constant temperature of $40^{\circ} \mathrm{C}$. Extraction time was fixed at $10 \mathrm{~min}$ according to the conditions previously described [7]. CE experiments were carried out in the same experimental conditions but replacing the ultrasonic tip by a mechanical stirrer (F 20520162, VELP Scientifica, Usmate Velate, Italy) at $1200 \mathrm{rpm}$. The experiments were performed according to the set-up previously established [38].

\subsection{Total Phenolic, Flavonoid and Carotenoids Contents}

The total phenolic content was estimated spectrophotometrically by the Folin-Ciocalteu reaction with some modifications [39]. Total phenolic content was expressed as milligrams of gallic acid equivalent per gram of dry plant extract (mg GAE/g DM). The identification and quantification of the major phenolic compounds present in the olive and fig leaves was carried out on TripleTOFTM 5600 (AB SCIEX) LC-MS/MS system equipped with Agilent 1260 Infinity (Agilent, Waldbronn, Germany). The MS acquisition was performed in the negative mode in the range between 80 and $1200 \mathrm{~m} / \mathrm{z}$, following the experimental procedure and methodology described in our previous work [38]. The flavonoid content was determined according to Sakanaka, Tachibana, and Okada [40]. (+)-Catechin was used for the analytical curve. The results were expressed as $\mathrm{mg}$ of catechin equivalent (CT) per gram of dry plant extract (mg CT/g DM). The extraction and quantification of total carotenoids was carried out in accordance to Lee and Castle [41]. All the analyses were performed in triplicate.

\subsection{Antioxidant Capacity and Anti-Inflammatory Effects}

The antioxidant activity was determined using the ABTS method [42]. The results, obtained from triplicate analyses, were expressed as mmol Trolox equivalent per gram of dry plant extract-mmol Trolox/g. The in vitro anti-inflammatory properties of extracts were assessed using a cell-reporter 
plasmid pNiFty2-SEAP (Invivogen) in HT-29 cells (human colon adenocarcinoma). In brief, HT-29 reporter-cells were seeded at 70.000 cells/well in 96-well plates and grown $24 \mathrm{~h}$ before the experiment. To analyze the NF- $\mathrm{KB}$ activation, cells were stimulated with/without a pro-inflammatory signal with TNF- $\alpha(20 \%)$ in the presence or absence of extracts (10 $\mu \mathrm{L}$ from each extract). After $24 \mathrm{~h}$ of stimulation, SEAP (secreted alkaline phosphatase) activity was quantified using $p$-nitrophenyl phosphate, as phosphatase substrate, in the supernatant according to the manufacturer's instructions (Thermo Scientific, Ref.: 37620). The yellow-colored reaction products were detected using a microplate reader (Multiskan Ascent, Thermo-Fischer Scientific, Waltham, Massachusetts, USA) at $414 \mathrm{~nm}$ and the results were expressed as $\%$ of inhibition of TNF- $\alpha$.

\subsection{Effect of Extracts on Bacterial Growth}

The effect of leaves extracts on the bacterial growth was checked by the use of specific strains selected in base of their potential beneficial properties as probiotics and other, based on their potential foodborne and pathogenic properties. The strains used probiotics were Lactobacillus casei BL23 and Bifidobacterium lactis NCC2818, whereas the potential foodborne bacteria were Listeria innocua CECT 910, Salmonella enterica CECT 4138 and Staphylococcus aureus CECT 86. Probiotic strains were grown in MRS and MRS $+0.05 \%$ L-cysteine respectively in anaerobic and static conditions to $37^{\circ} \mathrm{C}$ during $20 \mathrm{~h}$ while the potential pathogens were growth in brain heart infusion (BHI) medium in aerobic conditions to $37^{\circ} \mathrm{C}$ overnight.

Bacterial growth was monitored in presence or absence of $20 \mu \mathrm{L}$ of the different extracts. Overnight cultures for each strain were collected by centrifugation inoculated to a final optical density at $595 \mathrm{~nm}$ of 0.05 in a $200 \mu \mathrm{L}$ of broth medium in a 96 well microtiter plates and incubated at $37^{\circ} \mathrm{C}$. Changes in optical density at $595 \mathrm{~nm}$ were registered in a POLARStar reader (BMG Labtech, Ortenberg, Germany) and strains growth data were modelled by using the Gompertz equation [43] in order to mathematically describe the microbial growth and compute the specific growth rate in the exponential phase and optical density in the stationary one.

\subsection{Statistical Analyses}

Results were expressed as means followed by the standard deviation $(n=3)$. Significant differences between the results were calculated by one-way analysis of variances (ANOVA). Tukey's test was applied to compare the mean values [44]. All statistical analyses were performed using the software Statgraphics ${ }^{\circledR}$ Centurion XV (Statpoint Technologies, Inc., Virgin Islands, VI, USA).

\section{Conclusions}

Fig and olive leaves extract properties were dependent on extraction methodology (conventional or ultrasonically-assisted) and the solvent (aqueous or hydroethanolic). The combination of those factors affected the total phenolic, flavonoid and carotenoids content as well as the antioxidant and anti-inflammatory properties as well as affected the growth of different bacterial strains. Moreover, it seems that the use of extracts obtained from fig and olive leaves could have the potential to kill two birds with one stone and addressing both the stimulation of commensal and beneficial microbiota growth such as Lactobacillus, while inhibiting growth of pathogenic strains. However, it would be necessary to study the appropriate combination of polyphenols, as it seems the activity on microbial growth differs according to the type of polyphenol. Further research is of paramount importance in order to address the scaling-up of the ultrasonic assisted extraction for industrial purposes. Main aspects to be analyzed are related to the configuration of the ultrasonic emitter and the extraction vessel, the increase of the ratio dried material-solvent and the design of the cooling system to keep mild temperatures during the ultrasonic assisted extraction. 
Author Contributions: F.J.B., J.V.G.-P. and M.C.C. designed the study; R.A., T.Ž., C.A. conducted the experiments and analyzed the data with J.V.G.-P., A.R.J., J.M.L., D.G., M.C.C. and F.J.B.; R.A., T.Ž., C.A., F.J.B., M.C.C. wrote the first draft. All authors have read and agreed to the published version of the manuscript.

Funding: J.V.G.-P. acknowledges the financial support from the Spanish National Research Agency through the MEFPROC project (PCI2018-093161, Era-NET SUSFOOD2). F.J.B. and A.R.J. would like to thank Croatian Science Foundation for project: "High voltage discharges for green solvent extraction of bioactive compounds from Mediterranean herbs (IP-2016-06-1913)".

Acknowledgments: R.A. was supported by a STSM fellowship under the COST Action CA15136 EUROCAROTEN to develop this work. We would like to thank and acknowledge the study participants, the laboratories teams that contributed to this work.

Conflicts of Interest: The authors declare no conflict of interest.

\section{References}

1. Žugčić, T.; Abdelkebir, R.; Alcantara, C.; Collado, M.C.; García-Pérez, J.V.; Meléndez-Martínez, A.J.; Jambrak, A.R.; Lorenzo, J.M.; Barba, F.J. From extraction of valuable compounds to health promoting benefits of olive leaves through bioaccessibility, bioavailability and impact on gut microbiota. Trends Food Sci. Technol. 2019, 83, 63-77. [CrossRef]

2. Kapiszewska, M.; Sołtys, E.; Visioli, F.; Cierniak, A.; Zajac, G. The protective ability of the Mediterranean plant extract against the oxidative DNA damage. The role of the radical oxygen species and the polyphenol content. J. Physiol. Pharm. 2005, 56, 183-197.

3. Şahin, S.; Samli, R.; Tan, A.S.B.; Barba, F.J.; Chemat, F.; Cravotto, G.; Lorenzo, J.M. Solvent-Free Microwave-Assisted Extraction of Polyphenols from Olive Tree Leaves: Antioxidant and Antimicrobial Properties. Molecules 2017, 22, 1056. [CrossRef] [PubMed]

4. Şahin, S.; Elhussein, E.; Bilgin, M.; Lorenzo, J.M.; Barba, F.J.; Roohinejad, S. Effect of drying method on oleuropein, total phenolic content, flavonoid content, and antioxidant activity of olive (Olea europaea) leaf. J. Food Process. Preserv. 2018, 42, e13604. [CrossRef]

5. Ghazi, F.; Rahmat, A.; Yassin, Z.; Shazini Ramli, N.; Amira Buslima, N. Determination of total polyphenols and nutritional composition of two different types of Ficus carica leaves cultivated in Saudi Arabia. Pak. J. Nutr. 2012, 11, 1061-1065.

6. Putnik, P.; Barba, F.J.; Španić, I.; Zorić, Z.; Dragović-Uzelac, V.; \& Kovačević, D.B. Green extraction approach for the recovery of polyphenols from Croatian olive leaves (Olea europea). Food Bioprod. Process. 2017, 106, 19-28. [CrossRef]

7. Omar, S.H.; Kerr, P.G.; Scott, C.J.; Hamlin, A.S.; Obied, H.K. Olive (Olea europaea L.) Biophenols: A Nutriceutical against Oxidative Stress in SH-SY5Y Cells. Molecules 2017, 22, 1858. [CrossRef]

8. Rahmanian, N.; Jafari, S.M.; Wani, T.A. Bioactive profile, dehydration, extraction and application of the bioactive components of olive leaves. Trends Food Sci. Technol. 2015, 42, 150-172. [CrossRef]

9. Bubonja-Sonje, M.; Giacometti, J.; Abram, M. Antioxidant and antilisterial activity of olive oil, cocoa and rosemary extract polyphenols. Food Chem. 2011, 127, 1821-1827. [CrossRef]

10. Roselló-Soto, E.; Galanakis, C.M.; Brnčić, M.; Orlien, V.; Trujillo, F.J.; Mawson, R.; Barba, F.J. Clean recovery of antioxidant compounds from plant foods, by-products and algae assisted by ultrasounds processing. Modeling approaches to optimize processing conditions. Trends Food Sci. Technol. 2015, 42, 134-149. [CrossRef]

11. Chemat, F.; Vian, M.A.; Cravotto, G. Green extraction of natural products: Concept and principles. Int. J. Mol. Sci. 2012, 13, 8615-8627. [CrossRef] [PubMed]

12. Rombaut, N.; Tixier, A.-S.; Bily, A.; Chemat, F. Green extraction processes of natural products as tools for biorefinery. Biofuelsbioprod. Biorefining 2014, 8, 530-544. [CrossRef]

13. Khemakhem, I.; Ahmad-Qasem, M.H.; Catalán, E.B.; Micol, V.; García-Pérez, J.V.; Ayadi, M.A.; Bouaziz, M. Kinetic improvement of olive leaves' bioactive compounds extraction by using power ultrasound in a wide temperature range. Ultrason. Sonochemistry 2017, 34, 466-473. [CrossRef] [PubMed]

14. Barba, F.J.; Grimi, N.; Vorobiev, E. Evaluating the potential of cell disruption technologies for green selective extraction of antioxidant compounds from Stevia rebaudiana Bertoni leaves. J. Food Eng. 2015, 149, $222-228$. [CrossRef] 
15. Ahmad-Qasem, M.H.; Cánovas, J.; Barrajón-Catalán, E.; Micol, V.; Cárcel, J.A.; García-Pérez, J.V. Kinetic and compositional study of phenolic extraction from olive leaves (var. Serrana) by using power ultrasound. Innov. Food Sci. Emerg. Technol. 2013, 17, 120-129. [CrossRef]

16. Ílbay, Z.; S.,ahin, S.; Büyükkabasakal, K. A novel approach for olive leaf extraction through ultrasound technology: Response surface methodology versus artificial neural networks. Korean J. Chem. Eng. 2014, 31, 1661-1667.

17. Şahin, S.; Şamlı, R. Optimization of olive leaf extract obtained by ultrasound-assisted extraction with response surface methodology. Ultrason. Sonochem. 2013, 20, 595-602. [CrossRef]

18. Al-Rimawi, F.; Odeh, I.; Bisher, A.; Abbadi, J.; Qabbajeh, M. Effect of geographical region and harvesting date on antioxidant activity, phenolic and flavonoid content of olive leaves. J. Food Nutr. Res. 2014, 2, 925-930. [CrossRef]

19. Mopuri, R.; Ganjayi, M.; Meriga, B.; Koorbanally, N.A.; Islam, M.S. The effects of Ficus carica on the activity of enzymes related to metabolic syndrome. J. Food Drug Anal. 2018, 26, 201-210. [CrossRef]

20. Roby, M.H.H.; Sarhan, M.A.; Selim, K.A.-H.; Khalel, K.I. Evaluation of antioxidant activity, total phenols and phenolic compounds in thyme (Thymus vulgaris L.), sage (Salvia officinalis L.), and marjoram (Origanum majorana L.) extracts. Ind. Crop. Prod. 2013, 43, 827-831. [CrossRef]

21. Arvaniti, O.S.; Samaras, Y.; Gatidou, G.; Thomaidis, N.S.; Stasinakis, A.S. Review on fresh and dried figs: Chemical analysis and occurrence of phytochemical compounds, antioxidant capacity and health effects. Food Res. Int. 2019, 119, 244-267. [CrossRef] [PubMed]

22. Fidelis, M.; Do Carmo, M.A.V.; Cruz, T.M.; Azevedo, L.; Myoda, T.; Furtado, M.M.; Marques, M.B.; Sant'ana, A.S.; Genovese, M.I.; Oh, W.Y.; et al. Camu-camu seed (Myrciaria dubia)-from side stream to an antioxidant, antihyperglycemic, antiproliferative, antimicrobial, antihemolytic, anti-inflammatory, and antihypertensive ingredient. Food Chem. 2020, 310, 125909. [CrossRef] [PubMed]

23. Peyrol, J.; Riva, C.; Amiot, M.J. Hydroxytyrosol in the prevention of the metabolic syndrome and related disorders. Nutrients 2017, 9, 306. [CrossRef] [PubMed]

24. Richard, N.; Arnold, S.; Hoeller, U.; Kilpert, C.; Wertz, K.; Schwager, J. Hydroxytyrosol is the major anti-inflammatory compound in aqueous olive extracts and impairs cytokine and chemokine production in macrophages. Planta Med. 2011, 77, 1890-1897. [CrossRef]

25. Pan, M.-H.; Lai, C.-S.; Ho, C.-T. Anti-inflammatory activity of natural dietary flavonoids. Food Funct. 2010, 1, 15-31. [CrossRef]

26. Medina, E.; Romero-Gil, V.; Garrido-Fernández, A.; Arroyo-López, F.N. Survival of foodborne pathogens in natural cracked olive brines. Food Microbiol. 2016, 59, 104-111. [CrossRef]

27. Refaat, J.; Yehia, S.Y.; Ramadan, M.A.; Kamel, M.S. Rhoifolin: A review of sources and biological activities. Int. J. Pharm. 2015, 2, 102-109.

28. Alvarez, M.D.L.A.; Debattista, N.B.; Pappano, N.B. Synergism of flavonoids with bacteriostatic action against Staphylococcus aureus ATCC 25923 and Escherichia coli ATCC 25 922. Biocell 2006, 30, 39-42.

29. Basile, A.; Sorbo, S.; Giordano, S.; Ricciardi, L.; Ferrara, S.; Montesano, D.; Ferrara, L. Antibacterial and allelopathic activity of extract from Castanea sativa leaves. Fitoterapia 2000, 71, S110-S116. [CrossRef]

30. Nayaka, H.B.; Londonkar, R.L.; Umesh, M.K.; Tukappa, A. Antibacterial attributes of apigenin, isolated from Portulaca oleracea L. Int. J. Bacteriol. 2014, 2014, 1-8. [CrossRef]

31. Rodríguez Vaquero, M.J.; Alberto, M.R.; de Nadra, M.C. Antibacterial effect of phenolic compounds from different wines. Food Control. 2007, 18, 93-101. [CrossRef]

32. Duda-Chodak, A.; Tarko, T.; Satora, P.; Sroka, P. Interaction of dietary compounds, especially polyphenols, with the intestinal microbiota: A review. Eur. J. Nutr. 2015, 54, 325-341. [CrossRef] [PubMed]

33. Lee, H.C.; Jenner, A.M.; Low, C.S.; Lee, Y.K. Effect of tea phenolics and their aromatic fecal bacterial metabolites on intestinal microbiota. Res. Microbiol. 2006, 157, 876-884. [CrossRef] [PubMed]

34. Duda-Chodak, A. The inhibitory effect of polyphenols on human gut microbiota. J. Physiol. Pharm. Off. J. Pol. Physiol. Soc. 2012, 63, 497-503.

35. Kawabata, K.; Yoshioka, Y.; Terao, J. Role of intestinal microbiota in the bioavailability and physiological functions of dietary polyphenols. Molecules 2019, 24, 370. [CrossRef]

36. Ahmad-Qasem, M.H.; Cánovas, J.; Barrajón-Catalán, E.; Carreres, J.E.; Micol, V.; García-Pérez, J.V. Influence of olive leaf processing on the bioaccessibility of bioactive polyphenols. J. Agric. Food Chem. 2014, 62, 6190-6198. [CrossRef] 
37. Fernandes, F.A.N.; Rodrigues, S.; Cárcel, J.A.; García-Pérez, J.V. Ultrasound-assisted air-drying of apple (Malus domestica L.) and its effects on the vitamin of the dried product. Food Bioprocess. Technol. 2015, 8, 1503-1511. [CrossRef]

38. Abdelkebir, R.; Alcántara, C.; Falcó, I.; Sánchez, G.; Garcia-Perez, J.V.; Neffati, M.; Collado, M.C. Effect of ultrasound technology combined with binary mixtures of ethanol and water on antibacterial and antiviral activities of Erodium glaucophyllum extracts. Innov. Food Sci. Emerg. Technol. 2019, 52, 189-196. [CrossRef]

39. Singleton, V.L.; Orthofer, R.; Lamuela-Raventós, R.M. Analysis of total phenols and other oxidation substrates and antioxidants by means of Folin-Ciocalteu reagent. Methods Enzym. 1999, 299, 152-178.

40. Sakanaka, S.; Tachibana, Y.; Okada, Y. Preparation and antioxidant properties of extracts of Japanese persimmon leaf tea (kakinoha-cha). Food Chem. 2005, 89, 569-575. [CrossRef]

41. Lee, H.; Castle, W.S. Seasonal changes of carotenoid pigments and color in hamlin, earlygold, and budd blood orange juices. J. Agric. Food Chem. 2000, 49, 877-882. [CrossRef] [PubMed]

42. Re, R.; Pellegrini, N.; Proteggente, A.; Pannala, A.; Yang, M.; Rice-Evans, C. Antioxidant activity applying an improved ABTS radical cation decolorization assay. Free Radic. Biol. Med. 1999, 26, 1231-1237. [CrossRef]

43. Zwietering, M.H.; Jongenburger, I.; Rombouts, F.M.; Van't Riet, K. Modeling of the bacterial growth curve. Appl. Env.. Microbiol. 1990, 56, 1875-1881. [CrossRef]

44. Granato, D.; de Araújo Calado, V.M.; Jarvis, B. Observations on the use of statistical methods in Food Science and Technology. Food Res. Int. 2014, 55, 137-149. [CrossRef]

Sample Availability: Samples of the compounds are not available from the authors.

(C) 2020 by the authors. Licensee MDPI, Basel, Switzerland. This article is an open access article distributed under the terms and conditions of the Creative Commons Attribution (CC BY) license (http://creativecommons.org/licenses/by/4.0/). 